Article

\title{
Effect of Asymmetric Epoxy Coating/Metal Electrodes on the Electrochemical Noise Measurements Under Marine Alternating Hydrostatic Pressure
}

\author{
Fandi Meng ${ }^{1}$, Yushan Liu ${ }^{1}$, Li Liu ${ }^{1, *}$, Yu Cui ${ }^{2}$ and Fuhui Wang ${ }^{1,2}$ \\ 1 Shenyang National Laboratory for Materials Science, Northeastern University, Wenhua Road 3-11, \\ Shenyang 110819, China; fandimeng@mail.neu.edu.cn (F.M.); 21826059@zju.edu.cn (Y.L.); \\ fhwang@mail.neu.edu.cn (F.W.) \\ 2 Institute of Metal Research, Chinese Academy of Sciences, Wencui Road 62, Shenyang 110016, China; \\ ycui@imr.ac.cn \\ * Correspondence: liuli@mail.neu.edu.cn; Tel.: +86-24-8108-3918
}

Received: 11 November 2019; Accepted: 11 December 2019; Published: 12 December 2019

\begin{abstract}
Electrochemical noise (EN) is expected to be an in-situ evaluation method for coating performance in the real deep-ocean environment. The asymmetric factors of working electrodes (WEs) in EN configuration, including coating area, coating thickness, and coating impedance, were considered under marine alternating hydrostatic pressure (AHP) condition. The effect of WE asymmetry was discussed mainly by EN time records, wavelet analysis and shot noise method. The results indicated that coating impedance is the most important factor, and the coating with higher impedance contributes more to current noise in a pair of electrodes. The reason of asymmetry influence on EN measurements is mainly by the variation of average charge of current sources but not the current source frequency during the initial period of coating failure process. When the obvious corrosion of metal substrate happens, the corresponding EN proportion relationship between coating/metal WEs may be not exist.
\end{abstract}

Keywords: epoxy coating; electrochemical noise; asymmetric electrode; shot noise analysis; wavelet analysis; alternating hydrostatic pressure

\section{Introduction}

The corrosion of structural materials in the deep-sea environment is a critical issue to be solved urgently [1-3]. Employing organic coatings is one of the most widely used means to avoid corrosion of metals. However, coating deterioration cannot be timely detected in the deep-sea environment, resulting in a hidden corrosion destruction of the metal beneath the coating. Hence, developing a rapid evaluation or monitoring method for coating performance is one main direction of the present promising fields in organic coating, which has practical significance in the security of corresponding facilities.

Electrochemical noise (EN) is known as a relatively mature electrochemical technology in corrosion research $[4,5]$, since it has the characteristics of in-situ and nondestructive detection. According to the measurement of corrosion responses of metal substrate, EN can be effectively utilized to study the failure behavior of coating/metal system [6-10]. The previous study also demonstrated that EN is appropriate for the coating evaluation under marine alternating hydrostatic pressure (AHP) condition [11], and the residual effect of pressure variation can be reflected by potential spikes in EN time records. EN is expected to be used in the in-situ evaluation even monitoring of coatings under deep-sea environment. Nevertheless, to realize the span from laboratory to practical application, some understanding of EN theory still needs to be improved. 
In general, two nominally identical working electrodes (WEs) are used in the EN measurement [12]. The electrochemical current noise is measured as the galvanic coupling current between two WEs, the potential noise between the coupled WEs and reference electrode (RE) is measured simultaneously. Consequently, the noise resistance $R_{\mathrm{n}}$, which is defined as the standard deviation of potential divided by the standard deviation of current, is widely accepted [13]. However, this measurement method is based on the assumption that two WEs are quite similar and have a statistically same variation tendency. It is difficult to meet this requirement in the field, especially for the coating/metal system. Two separate but identical coated metals are rare to find in engineering application, in view of the geometric structure of materials is often uncontrollable [14]. In other words, there may be an asymmetry of working electrodes in the EN measurement.

Some researchers believe that asymmetric electrodes can make a better understanding in corrosion types and mechanisms [13-17]. In fact, the application of asymmetric metal electrodes has been made deliberately, in order to acquire the corrosion information on one of the two electrodes. Pistorius et al. [15] investigated the influence of electrode area and sampling rate on EN results. Corrosion mechanism can be obtained by using two electrodes with a large area ratio, since the anodic dissolution signal of smaller electrode is easy to be measured. Cottis et al. $[13,16]$ raised an interpretation that EN generates from the fluctuations in the values of resistance of a surface layer covering the anodic and/or cathodic phases. Therefore, the current noise is modulated by the instantaneous impedances. Hosseini et al. [17] believed that asymmetric configurations for EN measurement can increase the amplitude of current transients and detect a higher number of events. However, these asymmetric electrodes are mostly related to the uncoated metals. Further investigation on the asymmetry of the coating/metal system is still required to be carried out.

In practice, it is hardly to find two coatings with identical structural parameters to serve as standard measuring electrodes. Therefore, understanding the effect of electrode asymmetry on EN is essential, when utilized for evaluating or monitoring the coating/metal system. In this work, three factors of coating asymmetry that might affect EN data were considered, including electrode area, coating thickness, and coating impedance. Several groups of experiments with different asymmetric coating/metal electrode pairs were designed for EN measurement. The failure behavior of coating under AHP was analyzed by EN time records, shot noise, and wavelet methods. Furthermore, the corresponding calculation based on equivalent circuit of EN three-electrode system was performed, to discuss the correlation between asymmetric factors and EN measurements.

\section{Materials and Methods}

\subsection{Sample Preparation}

Epoxy resin-based coating was used in this study, which consisted of E44 epoxy resin (bisphenol A, Wuxi Resin Factory, Wuxi, China) as the binder, polyamide (TY-650, Tianjin Yanhai Chemical Co., Ltd., Tianjin, China) as the curing agent, and xylene as the solvent, with a mass ratio of 1:0.8:0.4 for stoichiometric reaction. The paint was stirred by a commercial magnetic stirrer for $0.5 \mathrm{~h}$, then remained stationary for $20 \mathrm{~min}$ to partially cure before brushing. The electrode sample was prepared by brushing the paints on the substrate, then it was cured in an oven with the following conditions: $40^{\circ} \mathrm{C}$ for $4 \mathrm{~h}$, $60{ }^{\circ} \mathrm{C}$ for $20 \mathrm{~h}$, and then room temperature $\left(25^{\circ} \mathrm{C}, 30 \% \mathrm{RH}\right)$ for 7 days. The substrate was Q235 steel sheets, which were ground to 240 -grit finish and then degreased and dewatered with a commercial acetone and ethanol, respectively. The surface roughness of the steel substrate was $15-20 \mu \mathrm{m}$. The steel sheets were welded to copper wires firstly for electrochemical experiment, then put them on the bottom of plastic vessels and inject the electronic packaging resin into the vessels for curing. The frontage of substrate was ground and the other sides were sealed. Finally, brush the paints on the frontage of substrate, and the electrochemical specimens were finished. The coating thickness was measured by a hand-held electronic gauge (PosiTector 6000, Defelsko, New York, NY, USA) according to ISO 2808 standard [18] procedures. To investigate the influences of different ratios of electrode area, coating 
thickness, and coating impedance on EN measurements, 6 groups of experiments were designed. The surface area of each squared steel substrate, and the coating thickness of each electrode are shown in Table 1.

Table 1. Design of asymmetric electrode configuration for electrochemical noise (EN) measurements.

\begin{tabular}{ccccccc}
\hline Group & $\begin{array}{c}\text { Area of WE1 } \\
\left(\mathbf{c m}^{\mathbf{2}}\right)\end{array}$ & $\begin{array}{c}\text { Area of WE2 } \\
\left(\mathbf{c m}^{\mathbf{2}}\right)\end{array}$ & $\begin{array}{c}\text { Thickness } \\
\text { of WE1 }(\boldsymbol{\mu m})\end{array}$ & $\begin{array}{c}\text { Thickness } \\
\text { of WE2 }(\boldsymbol{\mu m})\end{array}$ & Area Ratio & $\begin{array}{c}\text { Thickness } \\
\text { Ratio }\end{array}$ \\
\hline 1 & 9 & 9 & $100 \pm 10$ & $100 \pm 10$ & $1: 1$ & $1: 1$ \\
2 & 9 & 1 & $200 \pm 10$ & $200 \pm 10$ & $9: 1$ & $1: 1$ \\
3 & 16 & 1 & $100 \pm 10$ & $100 \pm 10$ & $16: 1$ & $1: 1$ \\
4 & 16 & 1 & $200 \pm 10$ & $200 \pm 10$ & $16: 1$ & $1: 1$ \\
5 & 1 & 1 & $100 \pm 10$ & $200 \pm 10$ & $1: 1$ & $1: 2$ \\
6 & 9 & 9 & $100 \pm 10$ & $200 \pm 10$ & $1: 1$ & $1: 2$ \\
\hline
\end{tabular}

\subsection{Electrochemical Measurements}

All the electrochemical experiments were performed by a Princeton P4000A Electrochemical Workstation (Ametek, Berwyn, IL, USA). Two coating/steel electrodes were used as the WE1 and WE2 for each experimental group in Table 1. A solid Ag/AgCl (saturated with $\mathrm{KCl}, \mathrm{E}$ (vs. SCE) = -0.157 V) was used as the RE and located in the middle of the WEs. All the potentials in the experiments were recorded versus $\mathrm{Ag} / \mathrm{AgCl} \mathrm{RE}$. The distance between coating surface and RE was less than $10 \mathrm{~mm}$, thus the solution resistance can be ignored. EN data was instantaneously recorded with a data sampling interval of $0.25 \mathrm{~s}(4 \mathrm{~Hz})$. In this work, the 5-order polynomial detrending method was utilized for the direct current (DC) drift removal of the EN data [19]. Electrochemical impedance spectroscopy (EIS) tests were performed in the frequency range from $100 \mathrm{kHz}$ to $0.01 \mathrm{~Hz}$. Applying a sinusoidal voltage of $50 \mathrm{mV}$ (rms) amplitude coupled with open circuit potential (OCP). A platinum sheet $(20 \mathrm{~mm} \times 20 \mathrm{~mm})$ was used as the counter electrode. ZSimpWin 3.50 software developed by Princeton Applied Research was utilized for analyzing the EIS data.

\subsection{Experimental Setup}

The experiments were performed in an Automatic Deep-Sea Simulation System, and details of the setup have been reported in [20]. The simulated AHP condition was obtained by the alternation between hydrostatic pressure at 6.0 MPa (equal to $600 \mathrm{~m}$ depth hydrostatic pressure in the ocean) and atmospheric pressure at $0.1 \mathrm{MPa}$. Each alternating pressure cycle consisted of high hydrostatic pressure for $6 \mathrm{~h}$ and ordinary pressure for $6 \mathrm{~h}$. The experiment started with high hydrostatic pressure, and the entire process lasted for 20 cycles $(240 \mathrm{~h})$ at room temperature $\left(25^{\circ} \mathrm{C}, 30 \% \mathrm{RH}\right)$. The test solution of 3.5 wt.\% NaCl was prepared with analytical grade $\mathrm{NaCl}$ and distilled water. The volume of the solution is more than $8000 \mathrm{~mL}$. In addition, the air in the autoclave is connected with open air at each stage of atmospheric pressure, therefore, the oxygen can be replenished in time. According to Henry's Law, the oxygen solubility increases with pressure at equilibrium. Therefore, the dissolved oxygen is adequate during the high hydrostatic pressure stage, since the equilibrium can be reach after a certain time.

\subsection{Theoretical Calculation Based on Equivalent Circuit Model}

Since EN result is the synthetical reflection of the behavior of two WEs, asymmetric factors of WEs will lead to a difference in EN values accordingly. It is assumed that the intact coatings (before serious corrosion of substrate) have the same physical properties in per unit volume, then coating can be seemed as a solution resistance in series with a parallel combination of a capacitor and a resistor, which is known as the simple Randles circuit model [21]. When the solution resistance is neglected due 
to a dominant impedance of organic coating, the coating impedance can be calculated by the following equation [22,23]:

$$
Z=\frac{1}{1 / R+j \omega C}=\frac{R(1-j \omega C R)}{1+(\omega C R)^{2}}
$$

where $j=\sqrt{-1}, \omega$ is the angular frequency. Thus, the electrode area $A$, coating thickness $d$ can be associated with coating impedance $Z$, according to the coating capacitance $C$ and coating resistance per unit area $R$ as follows:

$$
\begin{gathered}
C=\frac{A \varepsilon_{0} \varepsilon_{R}}{d} \\
R=\frac{\rho d}{A}
\end{gathered}
$$

where $\varepsilon_{0}$ the permittivity of vacuum, $\varepsilon_{R}$ the coating dielectric constant, and $\rho$ is the electrical resistivity. Take the log of both sides of Equation (1), then put Equations (2) and (3) into the equation, the derivation is calculated:

$$
\log (|Z|)=\log \left(\frac{\rho d}{A}\right)-\frac{1}{2} \log \left(1+\left(\omega \rho \varepsilon_{0} \varepsilon_{\mathrm{R}}\right)^{2}\right)
$$

It is easy to see that $\log (|Z|)$ is dependent on $d$ and $A$. Therefore, the impedance ratio of WE1 and WE2 can be calculated based on the assumption of consistent coating properties:

$$
\log \left(\frac{\left|Z_{2}\right|}{\left|Z_{1}\right|}\right)=\log \left(\left|Z_{2}\right|\right)-\log \left(\left|Z_{1}\right|\right)=\log \left(\frac{\rho d_{2}}{A_{2}}\right)-\log \left(\frac{\rho d_{1}}{A_{1}}\right)=\log \left(\frac{d_{2} A_{1}}{A_{2} d_{1}}\right)
$$

where $Z_{1}$ and $Z_{2}$ are the impedances of WE1 and WE2. Then the impedance ratios of asymmetric electrode groups are calculated and shown in Table 2 (All the values are relative to the WEs in Group 1). To verify the calculated values, the impedances of electrodes in the initial were experimentally measured (Table 2). In general, the measured values above are almost corresponding to the theoretical values. A certain deviation in coating impedance is inevitable due to the coating preparation and physical properties.

Table 2. Impedance ratios of asymmetric electrode groups calculated by Equation (5) and the related experimental values.

\begin{tabular}{ccccc}
\hline Group & $\begin{array}{c}\text { Calculated Impedance } \\
\text { Ratio }\left(Z_{\mathbf{1}} / \mathbf{Z}_{\mathbf{2}}\right)\end{array}$ & $\begin{array}{c}\text { Experimental } \\
\text { Value }\left(Z_{\mathbf{1}}\right) / \mathrm{G} \Omega\end{array}$ & $\begin{array}{c}\text { Experimental } \\
\text { Value }\left(\mathbf{Z}_{\mathbf{2}}\right) / \mathrm{G} \boldsymbol{\Omega}\end{array}$ & $\begin{array}{c}\text { Experimental } \\
\text { Impedance Ratio }\left(\mathbf{Z}_{\mathbf{1}} / \mathbf{Z}_{\mathbf{2}}\right)\end{array}$ \\
\hline 1 & 1 & 42.96 & 38.63 & $1.1 / 1$ \\
2 & $2 / 18$ & 75.89 & 534.44 & $2.0 / 13.8$ \\
3 & $0.6 / 9$ & 21.13 & 264.43 & $0.6 / 6.9$ \\
4 & $1.1 / 18$ & 26.00 & 378.15 & $0.7 / 9.8$ \\
5 & $9 / 18$ & 203.10 & 415.74 & $5.3 / 10.8$ \\
6 & $1 / 2$ & 32.95 & 55.75 & $0.9 / 1.4$ \\
\hline
\end{tabular}

The theoretical equivalent circuit model of EN has been developed, to interpret the EN formation process and to calculate the relevant parameters [16,24]. In the model, two electrodes have their respective anodic and cathodic reactions. The formation of a corrosion pit or other event is regarded as a current source, which involves an increase in time-dependent current noise. The anodic and cathodic resistances are time-independent in a short time. Thus, the measurable potential noise is the response of electrode resistances and the current source [13]. The equivalent circuit is represented as current sources in parallel with resistances, as shown in Figure 1. 


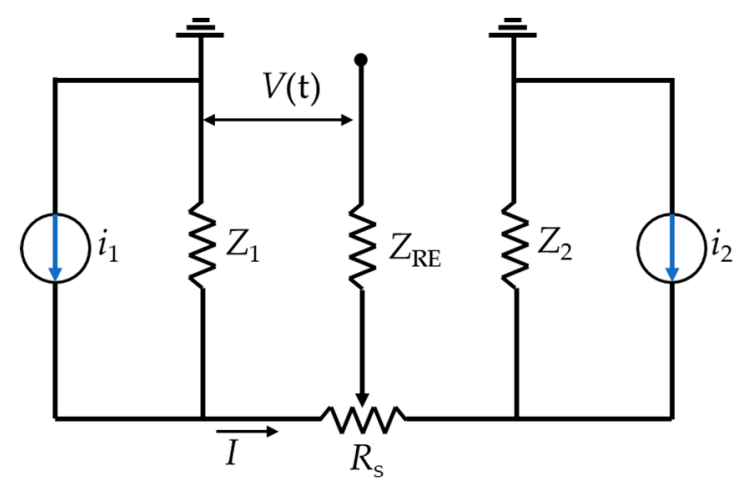

Figure 1. Equivalent electrical circuits model of EN (Reprinted with permission from [24]; Copyright 1997 IOP Publishing).

According to this model, $i_{1}$ and $i_{2}$ are the current sources of the WEs respectively, which may not be equivalent in absolute value and are not directly measurable. There may be various types of events taking place on the surface of electrodes, and the average electricity of each unit event is a certain value. Therefore, the current source can be regard as the sum of different events. It is assumed that when an instantaneous anodic source occurs on one electrode, the cathodic reactions that support this source occur on both electrodes. The contribution of the second electrode to the cathodic current flows through the ammeter, which is recorded as the current noise. Since the current noise sources of the WEs are supposed to be uncorrelated, the statistical current noise I measured by zero resistance amperometer (ZRA) can be derived as follows:

$$
I=\frac{Z_{1} i_{1}-Z_{2} i_{2}}{Z_{1}+Z_{2}}
$$

Accordingly, the potential noise $V$ and noise resistance $R_{\mathrm{n}}$ are

$$
V=-\frac{Z_{1} Z_{2}}{Z_{1}+Z_{2}}\left(i_{1}+i_{2}\right)
$$

As a conclusion, these equations cannot be solved directly, since four independent variables (the current noise and coating impedance of WEs) are unknown but only two measured values are available. However, it is possible to partially make the inferences by a simplified derivation. For the first case, we assume that current sources only occur on WE1 meanwhile no current source on WE2 $\left(i_{2}=0\right)$ at time $t$, as shown in Figure 2. Suppose $Z_{1} /\left(Z_{1}+Z_{2}\right)=X(0<X<1)$, then $I=i_{1} \cdot X$. When $Z_{2} \gg Z_{1}$, then $I \approx 0$; When $Z_{2} \ll Z_{1}$, then $I \approx i_{1}$. Hence, the range of $I$ is 0 to $i_{1}$. For the second case $\left(i_{1}=0\right)$, the range of $I$ is 0 to $-i_{2}$. For the third case $\left(i_{1}, i_{2} \neq 0\right)$, current sources simultaneously occur on WEs, $I=X \cdot i_{1}-(1-X) i_{2}$. The current noise $I$ is determined by the superposition of parts of $i_{1}$ and $i_{2}$. If $Z_{1}=Z_{2}, I=\left(i_{1}-i_{2}\right) / 2$. Otherwise, the coating with higher impedance contributes more to current noise $I$ than that with smaller impedance. 


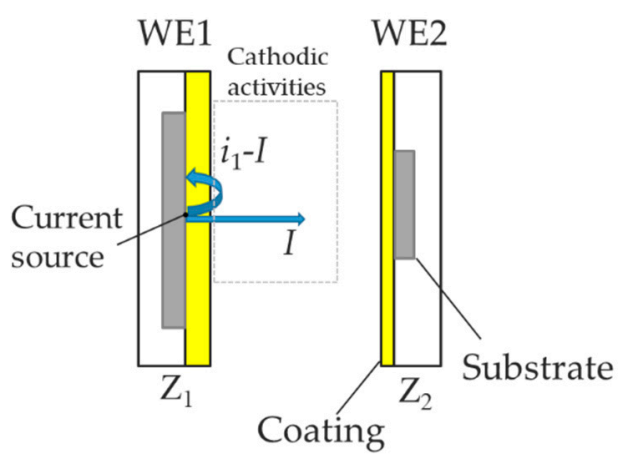

Figure 2. Schematic diagram of the simplified model $\left(i_{2}=0\right)$ for asymmetric electrodes.

\section{Results}

The process of coating failure under AHP essentially involves the following two steps: the water absorption and the corrosion of metal substrate. Regarding the EN of coated metal system, two stages can be distinguished depending on the corrosion characteristics of EN time records.

\subsection{EN Time Records in The Initial Failure Process of Coating}

For the coated metal system, the current noise can vary by several orders of magnitude due to the corrosion of metal. In order to provide direct comparisons, the $1024 \mathrm{~s}$ sections of current noise after $1 \mathrm{~h}$ immersion of different experimental groups are shown in Figure 3. All the electrochemical configurations must make sure the positive current spikes are generated from WE1. As the symmetric electrode configuration, the current fluctuations of Group 1 range from about $-1.2 \times 10^{-8}$ A to $1.5 \times 10^{-8} \mathrm{~A}$, which is larger than other groups due to the relatively lower impedance values of both WEs. When the configuration changes to asymmetry (Figure 3b for Group 2), it seems that positive and negative values don't have the similar amplitude. The current fluctuations vary from about $-2.0 \times 10^{-9} \mathrm{~A}$ to $4.0 \times 10^{-9} \mathrm{~A}$, since the impedance difference of WE1 and WE2 is almost an order of magnitude. In Figure 3c, the impedance difference increases to 1:16, thus the current noise values increase to about $-6.0 \times 10^{-9} \mathrm{~A}$ to $4.0 \times 10^{-9} \mathrm{~A}$, which demonstrates that a higher impedance difference can significantly enhance the amplitude fluctuations of current noise. The only difference between Group 3 and 4 is the coating thickness of WEs. Obviously, thicker samples (Group 4) have a lower signal in Figure 3d. As for the Group 5 (Figure 3e), the current fluctuations vary from about $-2.0 \times 10^{-9} \mathrm{~A}$ to $2.0 \times 10^{-9} \mathrm{~A}$, too small surface areas of WEs lead to the highest coating impedance, so that the configuration asymmetry seems insignificant. Group 6 was designed to compare with Group 1, since only the thickness of WE2 is different. The current fluctuations vary from about $-1.6 \times 10^{-8} \mathrm{~A}$ to $1.2 \times 10^{-8} \mathrm{~A}$, which is similar to that of Group 1. It indicates that the variation in thickness of one electrode may not bring visible effect to current noise.

In addition, the standard deviation and the skewness of current noise for each group are shown in Table 3, to quantitatively evaluate the amplitude of current and the symmetrical distribution on positive/negative direction, respectively [17]. Group 1 has the largest $\sigma_{I}$ value due to its far greater working area of both WEs. The theoretical skewness of Group 1 should be close to 0 (for impedance 1/1). Considering that the actual impedance of WE1 and WE2 in Group 1 are $42.96 \mathrm{G} \Omega$ and $38.63 \mathrm{G} \Omega$ respectively, our skewness result $(0.10$, positive direction) is very reasonable, which means that the coating with higher impedance contributes more to current noise than that with smaller impedance. Group 6 has a little lower $\sigma_{I}$ and an obvious negative direction skewness value (compared with Group 1), which is the effect by asymmetrical thickness. Regarding the other asymmetric factors, it is demonstrated that the greater impedance differences between WE1 and WE2, the larger amplitude of current ( $\sigma_{I}$ of Group 3 is bigger than that of Group 2). Their values of skewness are negative but similar, which suggest that the higher impedance WE has much more contribution to current noise, however, the degree of deviation between two groups is not obvious due to the weak average charge in the initial. 
It seems that thicker coating group can reduce the current amplitude as well as the asymmetrical degree, since coating thickness is the only difference between Group 4 and 3. According to the data of Group 5, it is possible to estimate that high impedance of coatings brings an almost symmetrical distribution about the zero value of skewness, even the thickness of WE1 and WE2 is deliberately asymmetric. It is because the levels of current noise are quite low, the variation in current noise is not obvious in the initial time, resulting in a deviation of skewness from theoretical value. In order to show the dependence between the current noise characteristics and the electrochemical impedance, the $\sigma_{I}$ value and the impedance of WEs in each group are given in Figure 4. Comparing the $\sigma_{I}$ results of different groups in Table 3, it indicates that the amplitude of current is lower, the asymmetrical distribution on positive/negative direction (i.e., the skewness) is not more obvious. There is no obvious relationship between the skewness and the impedance ratio in a single group in the initial immersion time, which may be due to the low current noise from both working electrodes.

(a)

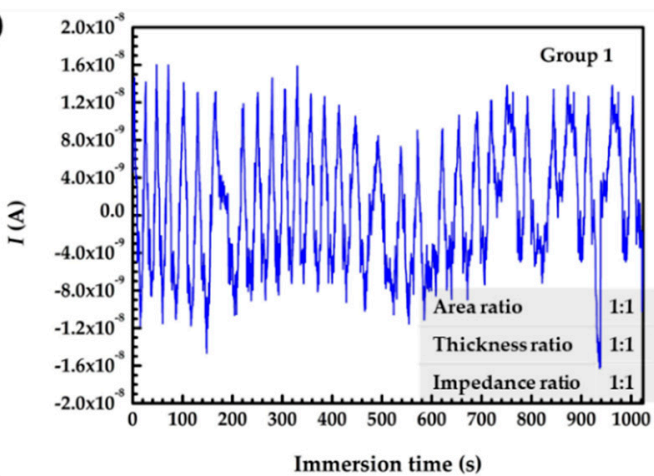

(c)

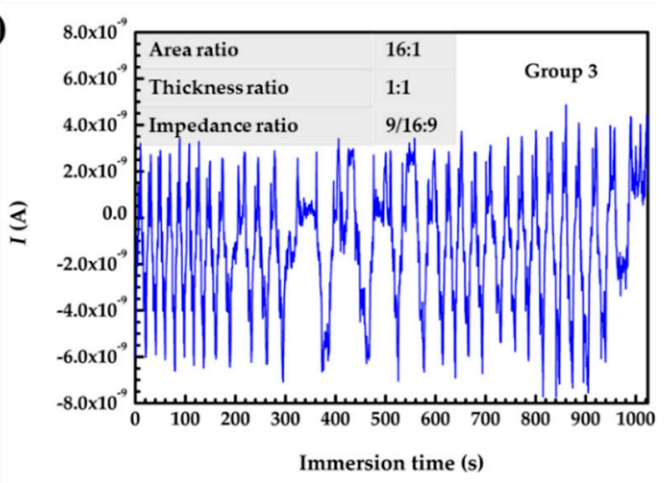

(e)

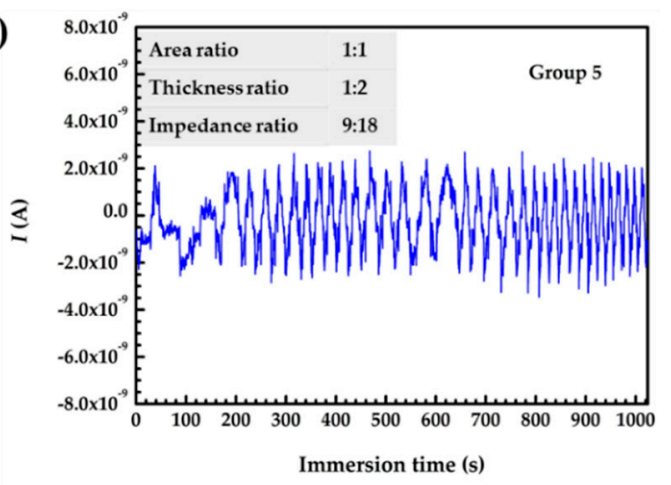

(b)

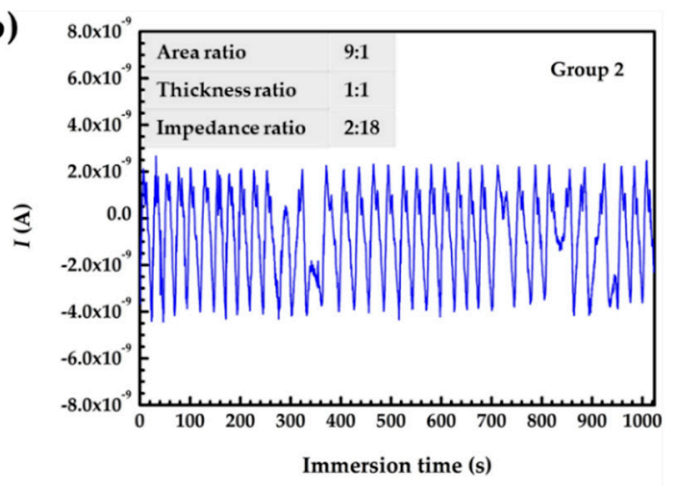

(d)

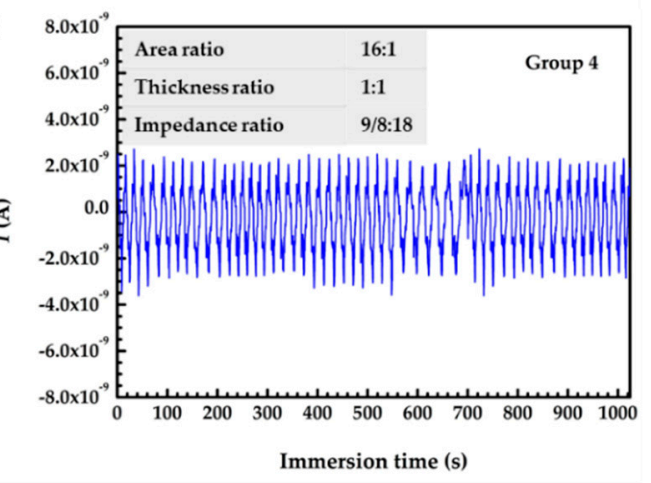

(f)

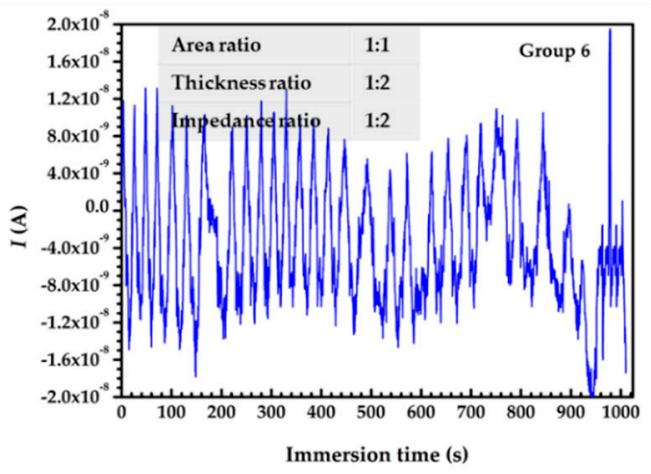

Figure 3. Electrochemical current noise section records of $1024 \mathrm{~s}$ data after $1 \mathrm{~h}$ immersion under alternating hydrostatic pressure (AHP): (a) data of Group 1; (b) data of Group 2; (c) data of Group 3; (d) data of Group 4; (e) data of Group 5; and (f) data of Group 6. 


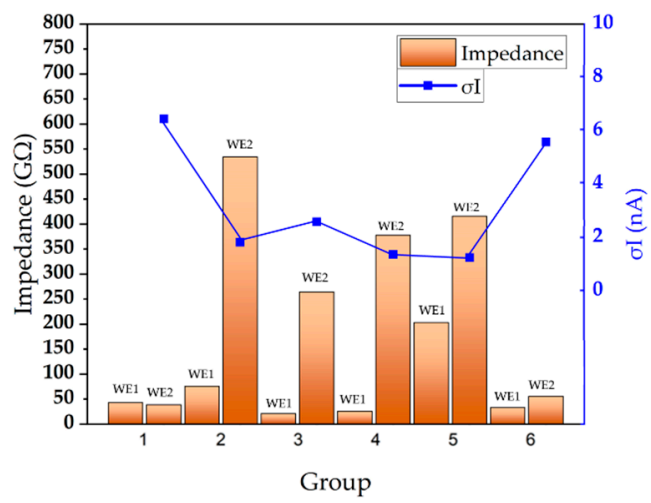

Figure 4. The correlation between current noise characteristics $\left(\sigma_{\mathrm{I}}\right)$ and electrochemical impedance for all the groups.

Table 3. Statistical values of current noise data for 6 groups in Figure 3.

\begin{tabular}{ccc}
\hline Parameters & $\boldsymbol{\sigma}_{\mathbf{I}}(\mathbf{n A})$ & Skewness \\
\hline 1 & 6.44 & 0.1 \\
2 & 1.82 & -0.23 \\
3 & 2.58 & -0.25 \\
4 & 1.36 & -0.088 \\
5 & 1.24 & 0.03 \\
6 & 5.58 & -0.285 \\
\hline
\end{tabular}

\subsection{EN Time Records after Remarkable Corrosion of Metal Substrate}

From the results above, a certain proportion of impedance between WEs can affect the EN measurement accordingly. However, the inhomogeneous structure of coatings causes a variation of physical properties from the microscopic angle, with a random distribution across the film [14]. Due to the presence of micro defects and inconsistency of physical and/or chemical properties, several localized corrosion of metal or localized damage of coating can significantly change the impedance performance. The dielectric constant and the coating resistivity may have different variations for WEs. Therefore, the impedance values of WEs after AHP immersion may be different even if the initial impedances are similar. That is, the case of impedance difference tends to change irregularly. Figure 5 is the macroscopic coating surfaces of WEs on the same scale in Group 3 after immersion of $120 \mathrm{~h}$. It is observed that WE2 was corroded more seriously. The failure rate of WE2 is not equal to that of WE1, which is confirmed by impedance modulus results in Figure 6. $|Z|$ of WE1 is about 3 orders of magnitude larger than that of WE2. Therefore, it can be deduced from Equation (6) that the measured current noise records should be dominated by the corrosion information of WE1. Figure 7 is a typical current noise section in Group 3 after $120 \mathrm{~h}$ immersion. The current amplitude is about $10^{-6} \mathrm{~A}$ on the positive direction, which is the opposite of what had been observed in the initial. The real information about WE2 can barely be provided by the apparent current noise, even the corrosion on this electrode is serious. 


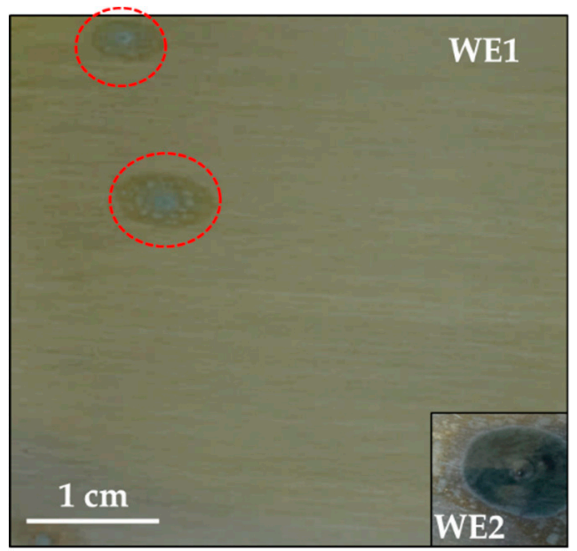

Figure 5. Optical surface morphology of working electrode 1 (WE1) and working electrode 2 (WE2) in Group 3 on the same scale after immersion of $120 \mathrm{~h}$.

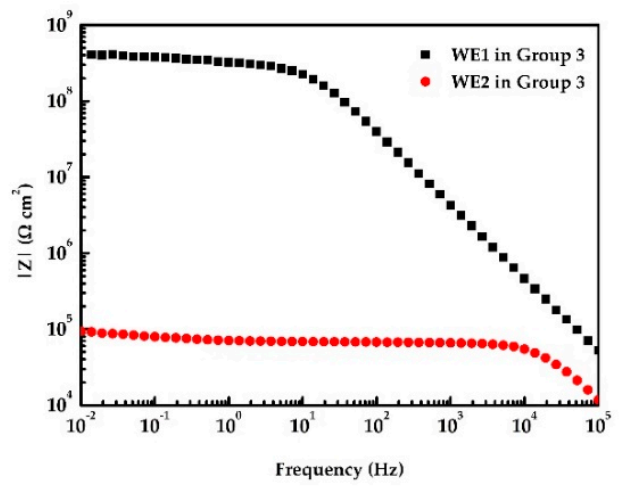

Figure 6. Impedance modulus of WE1 and WE2 in the Group 3 after immersion of $120 \mathrm{~h}$.

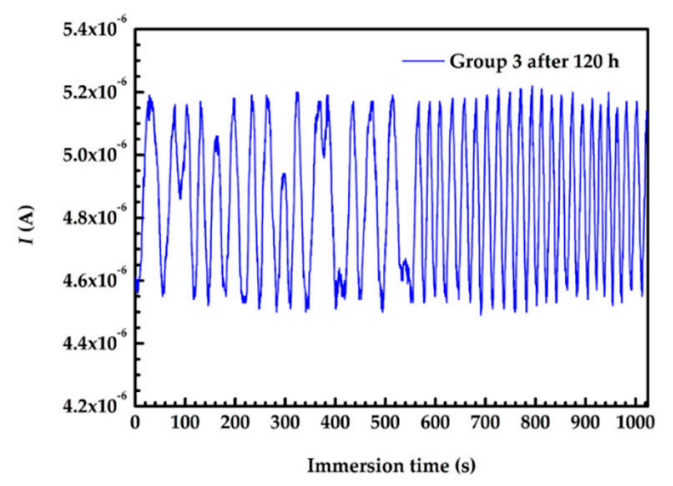

Figure 7. Typical current noise section of $1024 \mathrm{~s}$ data of Group 3 after $120 \mathrm{~h}$ immersion.

\section{Discussion}

In order to analyze the nature of EN results for each group in the initial, wavelet transformation of noise data was utilized. The relative energy ratios of processes with different time constants are calculated, which form the energy distribution plot (EDP) in representing different failure mechanism of the coating $[25,26]$. Figure 8 is the EDP of current noise of each group after $12 \mathrm{~h}$. The corresponding crystal cells (D1, D2, ..., D8) mean the contribution of each grain to the overall signal. Generally, the corrosion process especially localized corrosion, is faster than other processes (such as diffusion process) on the electrode surface. Therefore, the higher and lower order relative energies originate from different electrode processes. In Figure 8, the EDP diagrams of all groups show the same characteristics: the vast majority of energy distribution is located in D7, D8 cells, and the corresponding time constant 
is 32-128 s slow process [7]. Combined with the previous analysis of coating failure process, it can be concluded that D7, D8 cells in each group represent the solution diffusion step. On the contrary, the D1 to D3 cell series, which have small time constants (about $0.25-2 \mathrm{~s}$ ) and represent the corrosion process, are not the main part. It indicates that water diffusion process is the dominant step. The relative energy ratios of all the groups are almost the same, which suggest that the coatings of 6 groups essentially are at the same state of failure process, although their current noise fluctuations have obvious difference.

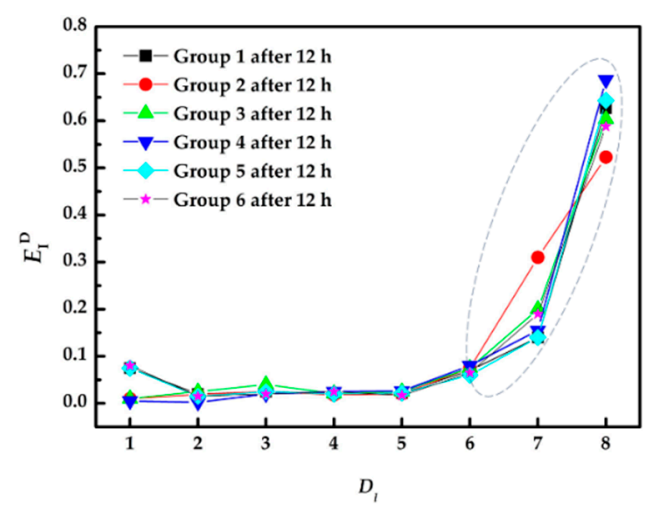

Figure 8. Energy distribution plot (EDP) of current noise of the $1024 \mathrm{~s}$ data for each group after $12 \mathrm{~h}$.

The shot noise theory was further studied to give an explanation in frequency-domain. Shot noise analysis assumes that the current noise generated by metal corrosion is composed of a series of discontinuous charge packets [27]. The maximum entropy method (MEM) was used to convert noise data from time domain to frequency domain for theoretical analysis. Two important parameters can be obtained, the frequency of corrosion event $f_{\mathrm{n}}$ and the average electric charge of each corrosion event $q$. The shot noise parameters can be calculated by the following formula [28]:

$$
\begin{gathered}
f_{n}=\frac{B^{2}}{\psi_{\mathrm{E}}} \\
q=\frac{\sqrt{\psi_{\mathrm{E}} \psi_{\mathrm{I}}}}{B}
\end{gathered}
$$

where $B$ is the Stern constant, it is a value related to the measurement system. For a certain corrosion system, $B$ is approximately identical, and a value of $0.025 \mathrm{~V}$ was used [29]. $\psi_{\mathrm{E}}$ and $\psi_{\mathrm{I}}$ are the values of low frequency limit $(0.01 \mathrm{~Hz})$ of power spectral density of potential and current noise, respectively. Since the same failure mechanism of all the groups have been confirmed by wavelet analysis, the EN signals can be regarded as the superposition of independent events, then a preliminary analysis on the corrosion situation can be performed by taking $f_{\mathrm{n}}$ and $q$ as the coordinates [30]. Figure 9 is the $f_{\mathrm{n}}$ versus $q$ plot of the coatings for different groups. The electrode surface and coating thickness were taken into consideration for the corrosion event analysis, which was normalized in the calculation. As shown in the figure, the scatters of 6 groups during the first $12 \mathrm{~h}$ overlap much. The corrosion event probabilities are almost the same after normalization, but the values of $q$ have slight differences. Compared with Group 1, the $q$ values of other groups statistically range from low to high, which mean that different coating impedance mainly affected the average charge of current sources, but the current source frequencies are almost the same during the same period. As for the obvious corrosion stage, the typical data in Group 3 after $120 \mathrm{~h}$ was proven in Figure 9. Higher $q$ and lower $f_{\mathrm{n}}$ indicate that the localized corrosion is serious, and the initial EN proportion relationship between WEs appears to no longer be the case. That is, when $\left|Z_{1}\right|>>\left|Z_{2}\right|$, the measured EN results may be not close to the real performance of the WE2 coating. 


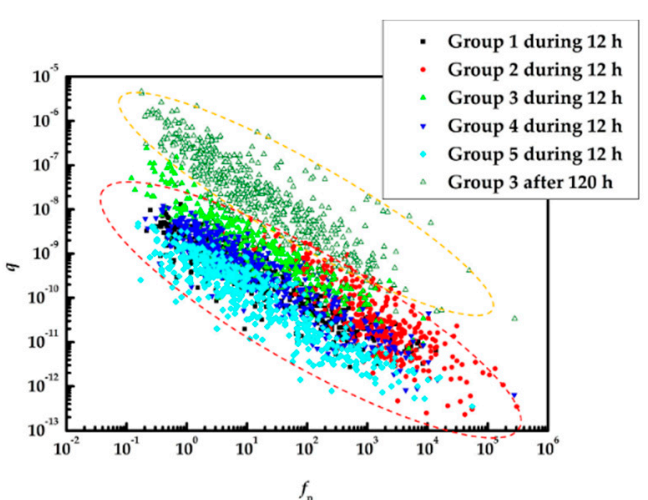

(a)

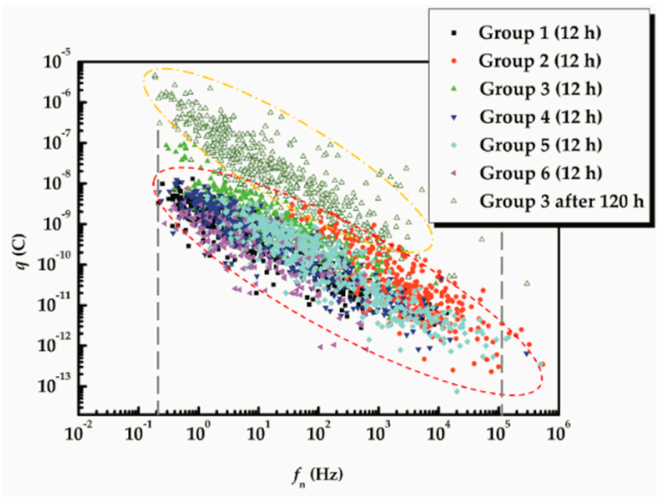

(b)

Figure 9. The $f_{n}$ versus $q$ plot of the coatings for different groups.

\section{Conclusions}

- The asymmetry of epoxy coating/metal electrodes (WE1 and WE2), including electrode area, coating thickness and coating impedance, significantly influences the electrochemical noise results in the initial. Coating impedance is the most important factor, and the coating with higher impedance contributes more to current noise than that with smaller impedance in a pair of electrodes.

- The asymmetric coating impedance influences EN measurements mainly by the variation of average charge of current sources but not the current source frequency before serious corrosion of metal substrate, since the same water diffusion mechanism can be confirmed during this period.

- When the obvious corrosion of metal substrate happens, the corresponding EN proportion relationship between coating/metal WEs may be invalid due to the different failure rate of the coatings. The coated metal with more serious corrosion cannot have enough information from EN results. Therefore, the utilization of EN results on the coatings with different failure states should be careful.

Author Contributions: Conceptualization, F.M. and L.L.; methodology, F.M.; validation, Y.L. and L.L.; formal analysis, F.M. and Y.C.; investigation, Y.L.; data curation, Y.L.; writing-original draft preparation, F.M.; writing-review and editing, L.L.; supervision, F.W.

Funding: This research was funded by the National Natural Science Foundation of China under the contract No. 51622106, the Fundamental Research Funds for the Central Universities under the contract No. N170203005, and China Postdoctoral Science Foundation under the contract No. 2018M640256.

Conflicts of Interest: The authors declare no conflict of interest.

\section{References}

1. Dexter, S.C. Effect of variations in sea water upon the corrosion of aluminum. Corrosion 1980, 36, $423-432$. [CrossRef]

2. Beccaria, A.M.; Poggi, G.; Castello, G. Influence of passive film composition and sea water pressure on resistance to localised corrosion of some stainless steels in sea water. Br. Corros. J. 1995, 30, $283-287$. [CrossRef]

3. Tian, H.Y.; Xin, J.C.; Li, Y.; Wang, X.; Cui, Z. Combined effect of cathodic potential and sulfur species on calcareous deposition, hydrogen permeation, and hydrogen embrittlement of a low carbon bainite steel in artificial seawater. Corros. Sci. 2019, 158, 108089. [CrossRef]

4. Bertocci, U.; Huet, F. Noise-analysis applied to electrochemical systems. Corrosion 1995, 51, $131-144$. [CrossRef]

5. Mansfeld, F. The electrochemical noise technique-Applications in corrosion research. In Noise and Fluctuations; Gonzalez, T., Mateos, J., Pardo, D., Eds.; Amer Inst Physics: Melville, NY, USA, 2005; Volume 780, pp. 625-630. 
6. Deya, M.C.; del Amo, B.; Spinelli, E.; Romagnoli, R. The assessment of a smart anticorrosive coating by the electrochemical noise technique. Prog. Org. Coat. 2013, 76, 525-532. [CrossRef]

7. Hasanzadeh, M.; Shahidi, M.; Kazemipour, M. Application of EIS and en techniques to investigate the self-healing ability of coatings based on microcapsules filled with linseed oil and $\mathrm{CeO}_{2}$ nanoparticles. Prog. Org. Coat. 2015, 80, 106-119. [CrossRef]

8. Ma, C.; Wang, Z.Q.; Behnamian, Y.; Gao, Z.M.; Wu, Z.; Qin, Z.B.; Xia, D.H. Measuring atmospheric corrosion with electrochemical noise: A review of contemporary methods. Measurement 2019, 138, 54-79. [CrossRef]

9. Xia, D.H.; Song, Y.; Song, S.Z.; Behnamian, Y.; Xu, L.K.; Wu, Z.; Qin, Z.B.; Gao, Z.M.; Hu, W.B. Identifying defect levels in organic coatings with electrochemical noise (EN) measured in single cell (SC) mode. Prog. Org. Coat. 2019, 126, 53-61. [CrossRef]

10. Xia, D.H.; Song, S.Z.; Behnamian, Y. Detection of corrosion degradation using electrochemical noise (EN): Review of signal processing methods for identifying corrosion forms. Corros. Eng. Sci. Technol. 2016, 51, 527-544. [CrossRef]

11. Meng, F.D.; Liu, L.; Li, Y.; Wang, F.H. Studies on electrochemical noise analysis of an epoxy coating/metal system under marine alternating hydrostatic pressure by pattern recognition method. Prog. Org. Coat. 2017, 105, 81-91. [CrossRef]

12. Arman, S.Y.; Ramezanzadeh, B.; Farghadani, S.; Mehdipour, M.; Rajabi, A. Application of the electrochemical noise to investigate the corrosion resistance of an epoxy zinc-rich coating loaded with lamellar aluminum and micaceous iron oxide particles. Corros. Sci. 2013, 77, 118-127. [CrossRef]

13. Cottis, R.A. The significance of electrochemical noise measurements on asymmetric electrodes. Electrochim. Acta 2007, 52, 7585-7589. [CrossRef]

14. Jamali, S.S.; Mills, D.J. A critical review of electrochemical noise measurement as a tool for evaluation of organic coatings. Prog. Org. Coat. 2016, 95, 26-37. [CrossRef]

15. Pistorius, P.C. Design aspects of electrochemical noise measurements for uncoated metals: Electrode size and sampling rate. Corrosion 1997, 53, 273-283. [CrossRef]

16. Curioni, M.; Cottis, R.A.; Di Natale, M.; Thompson, G.E. Corrosion of dissimilar alloys: Electrochemical noise. Electrochim. Acta 2011, 56, 6318-6329. [CrossRef]

17. Shahidi, M.; Jafari, A.H.; Hosseini, S.M.A. Comparison of symmetrical and asymmetrical cells by statistical and wavelet analysis of electrochemical noise data. Corrosion 2012, 68, 1003-1014. [CrossRef]

18. ISO 2808-2007 Paints and Varnishes-determination of Film Thickness; ISO: Geneva, Switzerland, 2007; p. 2007.

19. Bertocci, U.; Huet, F.; Nogueira, R.P.; Rousseau, P. Drift removal procedures in the analysis of electrochemical noise. Corrosion 2002, 58, 337-347. [CrossRef]

20. Tian, W.L.; Liu, L.; Meng, F.D.; Liu, Y.; Li, Y.; Wang, F.H. The failure behaviour of an epoxy glass flake coating/steel system under marine alternating hydrostatic pressure. Corros. Sci. 2014, 86, 81-92. [CrossRef]

21. Hinderliter, B.R.; Croll, S.G.; Tallman, D.E.; Su, Q.; Bierwagen, G.P. Interpretation of EIS data from accelerated exposure of coated metals based on modeling of coating physical properties. Electrochim. Acta 2006, 51, 4505-4515. [CrossRef]

22. Rammelt, U.; Reinhard, G. Application of electrochemical impedance spectroscopy (EIS) for characterizing the corrosion-protective performance of organic coatings on metals. Prog. Org. Coat. 1992, 21, 205-226. [CrossRef]

23. Rammelt, U.; Reinhard, G. Characterization of active pigments in damage of organic coatings on steel by means of electrochemical impedance spectroscopy. Prog. Org. Coat. 1994, 24, 309-322. [CrossRef]

24. Bertocci, U.; Gabrielli, C.; Huet, F.; Keddam, M. Noise resistance applied to corrosion measurements. 1. Theoretical analysis. J. Electrochem. Soc. 1997, 144, 31-37. [CrossRef]

25. Aballe, A.; Bethencourt, M.; Botana, F.J.; Marcos, M. Wavelet transform-based analysis for electrochemical noise. Electrochem. Commun. 1999, 1, 266-270. [CrossRef]

26. Liu, L.; Li, Y.; Wang, F.H. Pitting mechanism on an austenite stainless steel nanocrystalline coating investigated by electrochemical noise and in-situ afm analysis. Electrochim. Acta 2008, 54, 768-780. [CrossRef]

27. Cottis, R.A. Interpretation of electrochemical noise data. Corrosion 2001, 57, 265-285. [CrossRef]

28. Sánchez-Amaya, J.; Bethencourt, M.; González-Rovira, L.; Botana, F. Noise resistance and shot noise parameters on the study of IGC of aluminium alloys with different heat treatments. Electrochim. Acta 2007, 52, 6569-6583. [CrossRef] 
29. Stern, M.; Geaby, A.L. Electrochemical polarization. J. Electrochem. Soc. 1957, 104, 56-63. [CrossRef]

30. Meng, F.D.; Liu, L.; Cui, Y.; Zhang, T.; Li, Y.; Wang, F.H. A novel design of electrochemical noise configuration based on embedded-electrodes for in-situ evaluation of epoxy coating under marine alternating hydrostatic pressure. Prog. Org. Coat. 2019, 131, 346-356. [CrossRef] 